\title{
Rapid Heading technology of Coal Seam Containing iron sulfide Nodules
}

\author{
Xinglin Wen ${ }^{1, a}$, Mengmeng Dong, ${ }^{2, b}$, $\operatorname{Ran}^{3}{ }^{3, c}, K_{a i} \operatorname{Sun}^{3, d}$, \\ Zhongjian Zhang ${ }^{3, e}$ \\ ${ }^{1}$ Key Laboratory of Mining Disaster Prevention and Control, \\ Ministry of Education, SUST, Qingdao, Shandong 266590, China \\ ${ }^{2}$ TBEA SUNOASIS CO.LTD., Xinjiang 931100, China \\ ${ }^{3}$ College of Resources and Environmental Engineering, Shandong \\ University of Science and Technology, Qingdao, Shandong 266590, \\ China \\ awforst@126.com, b395355833@qq.com, c365237913@qq.com, \\ d894097218@qq.com, \\ e1041510585@qq.com
}

Abstract : 11605 coal face is the first working face in the lower series coal of Daizhuang coal mine, whose gateway drives along No.16 coal seam, containing iron sulfide with the thickness of about $300 \mathrm{~mm}$ under the roof of $400 \sim 500 \mathrm{~mm}$. To insure efficient driving of 11605 face gateway and meet the construction requirements, we should optimize the driving technology of hard parting, the supporting scheme, the work of water detection and water release.

Keywords: coal roadway tunneling, hard parting, timbering, water detection and water release
1. Preface

In recent years, with the development of comprehensive mechanized coal mining technology, higher driving speed is required for the continuation of production. As the upper series coal of Daizhuang coal mine is dwindling, mining for lower series coal is imperative. The problem has become more and more urgent during the driving process.

Because of the large Protodyakonov coefficient of iron sulfide parting, high-performance mechanized driving equipment cannot access to ensure the 
success of the driving project. Due to the huge material consumption and large amount of labor of the original supporting scheme, the driving speed is affected seriously. No.16 coal seam is threatened by the under tenth limestone water in immediate roof and Thirteenth limestone water along with Ordovician limestone water in floor. The strip mining area bellows villages mostly and roadway driving works is quite large. All factors affect the roadway layout and the roadway supersedure, thus the normal safety production of Daizhuang coal mine is affected seriously.

Therefore, based on the research status at home and abroad, firstly we should carry out mechanical test for this coal seam parting, after the theoretical calculation and field analysis, high-performance mechanized driving equipment can be chosen to ensure the hard parting flaking. Then, we should determine an appropriate bolting support system. Finally, make a suitable water detection and water release scheme for the roadway rapid heading, which is threatened by high water pressure.

\section{Influence factor analysis of rapid heading}

\subsection{Original heading modes}

Before 11605 track transportation tunnel
$300 \mathrm{~m}$, heading modes is blasting.

Proved by practice, original heading modes have the following disadvantages:

1. Slow driving speed and low efficiency with the monthly advance of 120-150m;

2. Blasting has a huge impact on rock shock and brings enormous damage, the difficulty of controlling the depth and width of the roadway, moreover, the roadway shape is different from original design, all these lead to the difficulties of the roadway maintenance. Furthermore, in the place of friable roof, the maintenance becomes more difficult, so the cost increases.

3. Blasting will bring about plenty of coal dust, increasing the workers' labor intensity and affecting the working condition.

\subsection{The original support scheme}

(1)Top supporting: as the roof of roadway is 10down limestone, when the roof is in good condition with limestone thickness larger than or equal to $3.0 \mathrm{~m}$ without fracture and fault we should use bare support forms, when the roof appeared local breaking, we should hang net anchor measures according to the site situation.

(2)Double working slope supporting: using such resin anchor rod as $\Phi 18 \times 1500$ 
mm rebar type in bare support, Row \& Line Space is $800 \times 1200 \mathrm{~mm}, 5$ root anchors of each row. Using reinforced support, Row \& Line space of $800 \times 800 \mathrm{~mm}$.

The practice proved the original support scheme has the following disadvantages:

1. Without clear system division of roadway roof, the supporting material and labor caused large consumption.

2. The great bolt support density restricted the excavation speed.

\subsection{The original water releasing scheme of the working face}

The rig is Zhejiang Hangzhou ZLY537 hydraulic machinery manufacturing LTD. Production of 150 meters.

Drilling field chamber arranged in tunneling place, the excavation team construct after the drilling construction completed. When the specified location was constructed, we begin the next round of drilling engineering.

Practice has proved that, releasing water has the following disadvantages.

1. Because the drilling field layout in tunneling head-on, excavation and ground water can't parallel operation, excavation need wait long time.

2.If the roadway adopted comprehensive mechanized excavation, drill footage per month will be improved to a great extent, but considering the small drilling rig power, it is impossible to realize long distance exploring water, the number of exploring water will be frequent.

\section{Hard dirt band cutting technology}

11605 track transportation tunnel designed along the 16 coal tunneling. Coal seam thickness is about 2 meters. In 400 500 meters under 16 coal roof of which stone thickness is about $300 \mathrm{~mm}$ iron sulfide, cutting plays bottom 400 $\mathrm{mm}$ is siltstone, hardness coefficients is larger. In order to improve the driving speed, it is necessary to do the coal seam dirt band experiment.

We process the acquisition of waste rock into standard rock specimen and the specimen's shape is cylinder. The test is doing in the world's most advanced MTS815.03 electro-hydraulic servo rock testing machine which was introduced from American and tested in college of natural resources and environmental engineering of Shandong university of science and technology, loading methods using displacement control, which can avoid the pressure reaching specimen ultimate strength damage quickly and without the peak pressure of the stress strain curve. Loading speed of pre-peak is $0.1 \mathrm{~mm} / \mathrm{s}$ and the post-peak of which is $0.2 \mathrm{~mm} / \mathrm{s}$.

The test results are shown in table.1 and rock uniaxial compression stress strain curve is shown in figure.1. 
Table.1 Daizhuang coal mine rock uniaxial compression test results

\begin{tabular}{c|cccccc}
\hline $\begin{array}{c}\text { specimen } \\
\text { number }\end{array}$ & $\begin{array}{c}\text { diameter } \\
\text { /mm }\end{array}$ & $\begin{array}{c}\text { height } \\
/ \mathrm{mm}\end{array}$ & $\begin{array}{c}\text { Breaking } \\
\text { load/KN }\end{array}$ & $\begin{array}{c}\text { Ultimate } \\
\text { strength } \\
\text { /MPa }\end{array}$ & coefficient & $\begin{array}{c}\text { elasticity } \\
\text { /MPa }\end{array}$ \\
\hline $1 \#$ & 48.58 & 70.70 & 276.733 & 149.298 & 14.93 & 17250.07 \\
$2 \#$ & 48.84 & 83.00 & 219.121 & 116.961 & 11.70 & 14514.66 \\
$3 \#$ & 48.78 & 85.74 & 216.404 & 115.796 & 11.58 & 18456.91 \\
$4 \#$ & 48.64 & 94.72 & 162.239 & 87.313 & 8.73 & 17613.38 \\
$5 \#$ & 48.64 & 89.22 & 309.06 & 166.36 & 16.63 & 24888.81 \\
average & & & & 127.15 & 12.71 & 18544.77 \\
\hline
\end{tabular}

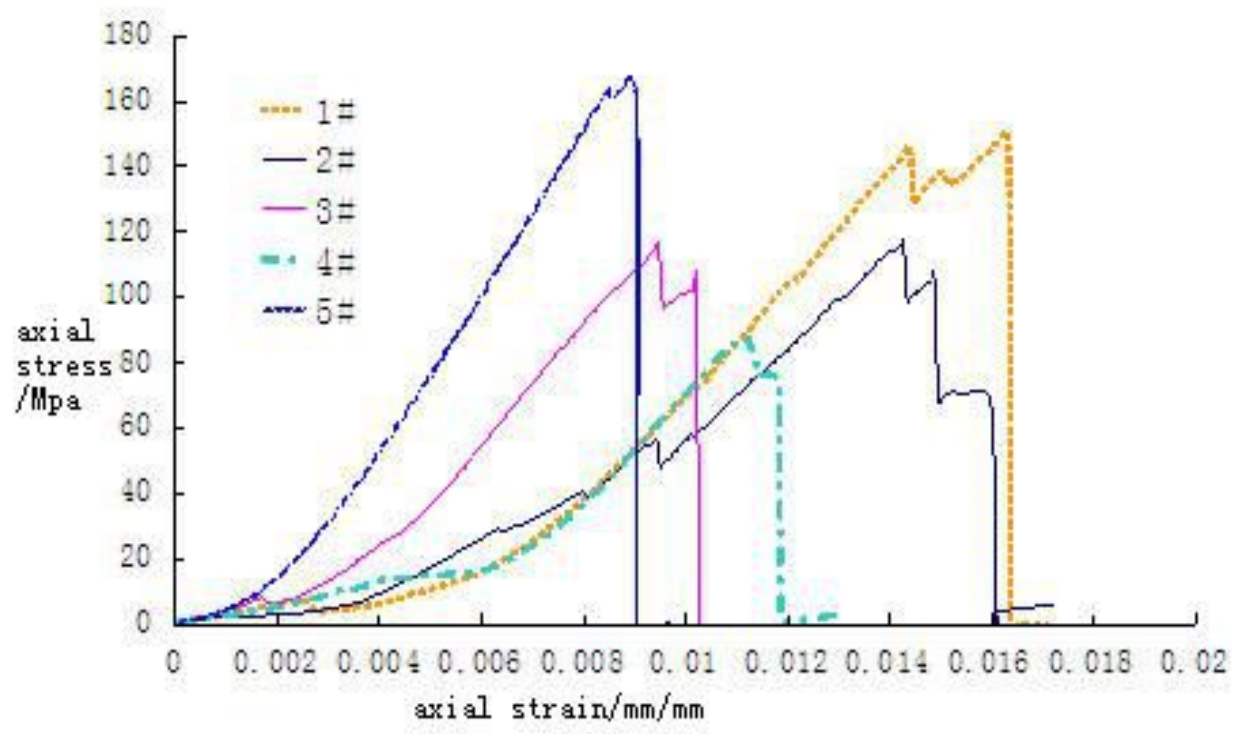

Fig.1 Rock uniaxial compression stress strain curve

Through the comparison and environment moisture of analysis, EBZ230 machine inconvenience; comprehensive cutting head is vertical-axis, tunneling machine belt and large cutting head drive is convenient, belt have a great cooperation, compact structure and it is easy to reduce the frequency of the get a flat cross section. Loading movement of the belt machine form is star wheal, operation tail; Walking mechanism using simple and driven by hydraulic the crawler, without track laying, motor to avoid working traction ability is great and it is 
good adaptability to floor; Dust removal way for the spray, this way make operation reliable and serves long life. Summarizing the above advantages, using EBZ230 roadheader construction, adopt the high power comprehensive tunneling machine, encounter in the process of excavation and floor strata can be directly cut.

Then through the field observation, after analyzing the properties of the iron sulfide, reasonable choose to install each part of the gun head of cutting pick. The premise in the process of cutting is the correct cutting direction, making full use of own weight of the tunneling machine and squeeze force to sides of gun head when the machine going forward to cut the gangue of iron sulfide, Solved the tunneling process of high strength iron sulfide thick hard cutting problem, improved the safety coefficient and excavation working efficiency.

\section{The optimization design of supporting}

Regard the stress of the roadway as a plane strain condition. Mechanics model is the beam structure that its two fixed end constraint and immediate roof with overburden uniform loading. The critical thickness of roof support is 2.5 meters ${ }^{[1]}$.

The roof supports ways are divided into three types:

(1)When the roof limestone thickness is more than or equal to 2.5 meters, and the roof is complete without fracture and fault, use the way of timbering.

(2) When the roof lithology changed, fault and roof crevice or limestone thickness is less than 2.5 meters, use the way of support.

(3)The support way of soft rock false roof.

Roof carries out drilling monitoring way. The drilling eyes of roof layout are as follows:

(1) When the roof is completed without fracture and fault, the detection results limestone 
thickness is more than 2.5 meters per 20 meters for roof limestone exploration.

(2) When the roof is uncompleted confronting with faults, fracture and so on, the detection of roof limestone thickness is more than 2.5 meters, roof limestone exploration timbering take places per 5 meters.

(3) When the roof is influenced by fault that its lithology changes or roof breakage and so on to strengthen supporting in time and take full section hanging net that no longer set out eyes on the roof. (4) Each 100 meters to the roof of roadway construction a depth of not less than the thickness of limestone eye in order to ascertain the actual roof limestone thickness and changes of lithology and the above detection on site mark and register and listing management.

\section{Drainage technology}

In order to alleviate the contradiction between the drivage and detecting water, and improve the efficiency of tunneling, we made the following optimization:

1. Change the drilling equipment and achieve the long distance water exploration

Using SGZ-ШA drilling rig, drill rod by $\Phi 50 \times 5.5 \mathrm{~mm}$ geological drill pipe, and the three wing alloy or PDC composite film series drilling bit to drill. The original ordinary drilling rig can only drill 150 meters total and average $10 \mathrm{~m}$ drilled by a class, but adopting the SGZ-ШA drilling rig, a class can achieve 20 meters, a hole only be drilled five days and the hole depth is 290 meters. Only in this way, can we achieve the long distance water exploring; ensure the safety of construction, and save plenty of time for tunnel excavation.

2. Drilling room arrangement To optimize the advanced drilling layout, by building drilling room for advance drilling on non production side instead of the original advancing hole arranged on head-on, we can reduce water inflow and solve the problem of water discharge affecting the 
drivage.

Drilling room is built on non production side of 11605 track transportation tunnel, the separation distance of it is 250 meters. The drill field specifications: $\mathrm{L} \times \mathrm{W} \times$ $\mathrm{H}=4 \mathrm{~m} \times 4 \mathrm{~m} \times 2.4 \mathrm{~m}$, The crossover distance is 25 meters.

\section{Benefit analysis}

1. Direct benefit (case of 11605 working face $)^{[2][3]}$.

With the project put into use, the task was finished 10.7 months in advance. If every staff's salary was 177 yuan per day, the project cost would be saved $10.7 \times 22$ days $\times 30$ people $\times 177$ yuan per day $=125$ million yuan.

Fully mechanized driving ensures the quality of roadway forming and little damage to surrounding rock, thus maintains the own strength of roadway surrounding rock utmost.At the same time, adopting the reasonable supporting scheme, the roadway isn't basically repaired in service

\section{5 working face}

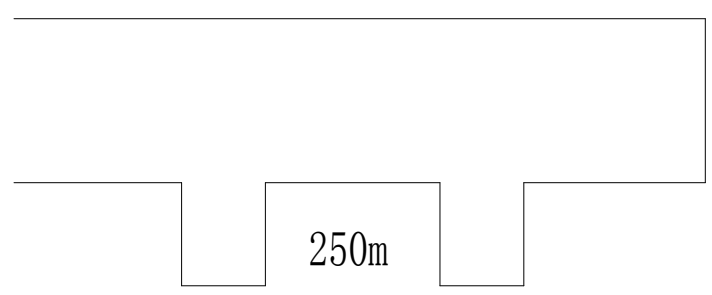

Fig.2 The arrangement of drilling room deadlines. The cost of roadway maintenance is 100 yuan per meter, the economize of roadway repairing is $100 \times 3200=32$ million yuan.

The saving fees of supporting materials are 11.5 million yuan. Each detonator is 1.5 yuan, each bit is 50 yuan, explosive is 5.5 yuan a kilo, and power consumption is 2.3 million yuan per month, the total cost savings are $(8.6 \times 5.5+29.4 \times 1.5-0.15$ $\times 50) \times 3200+115000-23000$ $=36$ million yuan.

To sum up, the direct benefit of 11605 working In total 193 million yuan.

2. Indirect benefit 
The task of track transportation tunnel was finished 10.7 months in advance, it would gain much time on alternate mining for Daizhuang Mine and keep the normal continuation of mine fields. The potential benefits of it are immeasurable.

\section{References}

[1] Qinqin Li. Feasibility study of naked support on K2 limestone nude under hard roof [D]. Anhui construction industry institute.2012:30-33
[2] Ruiguang Wang. Fulai Song. $\mathrm{Xi} \mathrm{Gu}$. The quick rock tunneling construction technique practice [J]. Zhongzhou coal. 2010(10) .

[3] Xizhu Chen. Yumin Geng. Guanghui Li. Lixin Li. Xing Li. EBZ230 tunneling machine in the application of rock tunneling [J]. Zhongzhou coal. 2010. 